Int. J. Curr. Res. Med. Sci. (2017). 3(2): 7-14

\section{International Journal of Current Research in Medical Sciences}

ISSN: 2454-5716

www.ijcrims.com

Volume 3, Issue 2 -2017

\title{
Pilot study of Sarva Noi Linga Chenduram for Lithontriptic activity in the management of renal calculi. (Kalladaippu)
}

\author{
Dr A. Punitha ${ }^{1 *}$, Dr S.Visweswaran ${ }^{2}$, Dr A. Rajendra kumar ${ }^{3}$, \\ Dr K.Manickavasakam ${ }^{4}$. \\ ${ }^{1}$ Department of Gunapadam \\ ${ }^{2}$ Lecturer, Department of Gunapadam, National Institute of Siddha, Chennai -47. \\ E-mail:svisu11@gmail.com \\ ${ }^{3}$ Research officer, SRRI,Puducherry. \\ ${ }^{4}$ Former Director, National Institute of Siddha, Chennai -47 \\ *Corresponding author: punidranbu@gmail.com
}

\begin{abstract}
Even though the treatment options are most available, incidence and recurrence of Renal calculi has not yet markedly reduced. The main aim of the study was to assess the efficacy of poly herbal formulation Sarva Noi Linga Chenduram for Renal calculi. It was diagnosed by clinical signs, symptoms , the presence and size of renal calculi was confirmed by Ultrasonagram. It was an open labeled, single center, prospective, pilot study conducted in 20 patients of renal calculi in National Institute of Siddha.130 mg of Sarva Noi Linga Chenduram was given with Raphanus sativus juice after meals twice a day for 30 days. After the treatment period there were prognosis of symptoms statistical analysis- paired ' $t$ ' test "P" value showed 0.240 which is moderately significant and for size of renal calculi it showed 0.001 which is highly significant. No significant change in most of the safety laboratory parameters was observed at the end of the study. Hence Sarva Noi linga Chenduram can be used in the treatment of Renal calculi.
\end{abstract}

Keywords: Sarva Noi Linga Chenduram, Siddha, Renal Calculi, Kalladaippu.

\section{Introduction}

Siddha System is one of the traditional and pioneer systems of medicine. Siddha medicines are broadly classified in to internal medicines and external medicines each constitutes 32 types. They are prepared from herbs, metals, minerals and biological resources. A total number of 4,448 diseases is mentioned in siddha text as well as with line of treatment.
Kalladaippu is one of the diseases mentioned in siddha text kalladaippu can be correlated with renal calculus which is the presence of stones in the kidney, ureters and bladder. Mankind has been affected by the urinary stones since centuries. Renal calculus, one of the most common urologic disorder. 
Archeological findings give profound evidence that humans have suffered from kidney and bladder stones for centuries. Bladder stones were more prevalent during older ages, but kidney stones became more prevalent during the past 100 years $^{1}$ The first evidence of urinary stone was found in Egyptian mummy E1amrah eygpt at 4800B.C.

The high incidence and recurrence rate contribute to making the urolithiasis a serious social problem. Nowadays, urolithiasis must be considered a 'disease in evolution' for several reasons, such as epidemiological changes, evolution of the methods used for diagnosis, and the treatment and prophylaxis of the population considered 'at risk' of stone disease. ${ }^{3}$

.The overall probability that an individual will form stones varies in different parts of the world. The risk of developing urolithiasis in adults appears to be higher in the western hemisphere (5-9\%) in Europe, $12 \%$ in Canada, $13-15 \%$ in the USA) than in the eastern hemisphere (1-5\%), although the highest risks have been reported in some Asian countries such as Saudi Arabia $(20.1 \%)^{4}$

It is estimated that at least $10 \%$ of the population in the industrialized part of the world is afflicted by urinary tract stone disease. ${ }^{5,6}$.Kidney stones are common in industrialized nations with an annual incidence of $0.5 \%$ to $1.9 \%$. In India upper and lower urinary tract stones occur frequently but the incidence shows wide regional variation?

The incidence of renal calculi is comparatively low in the southern part of country compared to other parts ${ }^{8}$ Urinary stone constitute one of the commonest diseases in our country and pain due to kidney stones is known as worse than that of labour pain. In India, approximately 5-7 million patients suffer from stone disease and at least $1 / 1000$ of Indian population needs hospitalization due to kidney stone disease ${ }^{2}$

In India upper and lower urinary tract stones occur frequently but the incidence shows wide regional variation. The incidence of renal calculi is comparatively low in the southern part of country compared to other parts ${ }^{8}$. It has been well documented that the incidence of urinary stones is higher in countries with warm or hot climates, probably due to low urinary output and scant fluid intake $^{2}$.

$12 \%$ of people have stone in their life time. Highest incidence of urinary stone in the age group of 30-45 years and declines after the age of $50.12 \%$ of men and $5 \%$ of women suffer from urinary stone by the age of $70.50 \%$ have their recurrence in 5-10 years.7-10 of every 1000 hospital admission is a renal stone.$^{2}$

First-degree relatives of stone-formers have a 216 times higher risk of developing renal stones when compared with the general population. In a stone-former, the probability of having a relative with stones may be as high as $35-65 \%$ as compared with a $5-20 \%$ probability in a nonstone-former. First-degree relatives of stoneformers have a 2-16 times higher risk of developing renal stones when compared with the general population. In a stone-former, the probability of having a relative with stones may be as high as $35-65 \%$ as compared with a $5-20 \%$ probability in a non-stone-former. ${ }^{4}$

Treatment options and conservative measures, as well as 'surgical' interventions have also been known for a long time. In the recent few days new modern techniques are available to treat renal calculi which are not cost effective to low and middle socio-economic group. Even though our current preventive measures are definitively good the incidence and recurrence has not yet reduced markedly.

Several siddha medicines evidenced lithontriptic activity in the management of renal calculi. Sarva Noi Linga chenduram is one of the herbo-mineral formulation which is mentioned in siddha text for kalladaippu? .

The ingredients of Sarva Noi Linga Chenduram are Lingam and Venkaram.. The efficacy of this drug has not been evaluated so far. Hence the researcher had selected Sarva Noi Linga Chenduram to evaluate its lithontriptic activity and therapeutic effect. 


\section{Materials and Methods}

For the pilot study Sarva Noi Linga Chenduram was prepared in Gunapadam laboratory,NIS Chennai.

\section{Collection and authentication of raw drug:}

The raw drugs were procured from raw drug store in Chennai and authenticated by competent authority of Department of Gunapadam.

\section{Preparation of the medicine:}

\section{Ingredients:}

Purified Lingam (Cinnabar) - $\quad 35 \mathrm{~g}$

Purified Venkaram (Borax) - $\quad 140 \mathrm{~g}$

\section{Purification methods:}

\section{Purification of Lingam ${ }^{10}$ :}

It was kept on a mud vessel and heated in low fire. The juices of Citrus lemon, Acalypa indica, cow's milk were mixed in equal proportions. The mixed liquid was poured drop by drop on lingam while heating.

\section{Purification of Venkaram ${ }^{11}$ :}

Venkaram ground by the citrus lemon juice and then dried it

\section{Method of medicine preparation:}

Lingam ground into tiny particles. Venkaram got placed in a mud vessel and heated in a low fire. When Venkaram started melting purified Lingam was sprinkled little by little. It had to be mixed well. Before melting of Venkaram all quantity of Lingam was sprinkled. After that the medicine was taken away from the heat. By the time, it got completely condensed. Then it was well ground in the kalvam and stored in an air tight container.

\section{Study Design :}

It was an open label, non-comparative, prospective, pilot study. The study protocol and related documents were reviewed and approved by institutional ethics committee at National Institute of Siddha Chennai- 47, India. Approval number is NIS/IEC/2011/3/13a-24/12/2011. Based on the protocol approved by IEC,NIS the study was conducted on renal calculi patients. The study was conducted in National Institute of Siddha, Ayothidass Pandithar hospital, chennai 47.Patients who was reporting at OPD of Ayothidass Pandithar hospital with inclusion criteria were subjected to screening \& documented using screening proforma. As per the patients satisfying the inclusion criteria the pilot study was conducted on kalladaippu (renal calculi) patients. Sample size was 20 patients and were selected by simple random method.

\section{Inclusion criteria:}

Patients of both sexes of age ranging from $16-80$ years with an average weight of 45-85 kg.Patients with symptoms of colicky pain from loin to groin,burning micturition,frequency of micturition ,dysuria ,vomiting,nausea, fever ,heamaturia were included with any of 4 clinical symptoms.Patients willing to undergo X-ray KUB,U.S.G abdomen ,blood and urine investigation before and after treatment and who were willing to attend OPD once in 7 days.

\section{Exclusion criteria:}

Patients with Renal failure, Liver disorder, Pregnancy, lactation and any other serious illness were excluded. Patients taking any other medications were excluded and persons having known hypersensitivity to ingredients used in study drug were excluded.

\section{Conduct of the study:}

Renal calculi patients who were satisfied the inclusion and exclusion criteria were admitted to the clinical trial. Patient's informed consent was obtained. Routine haematological, urine investigations along with U.S.G abdomen were assessed before and after treatment. Trial drug was issued to them once in 7 days for out patients. Every visit they were assessed clinically. For inpatients the trial drug were issued daily. On 
baseline visit, 23 patients were enrolled, who met the inclusion and exclusion criteria. All enrolled subjects were assigned in a single group and were given 'Sarva Noi Linga chenduram.' a polyherbal formulation in a dose of $130 \mathrm{mg}$ twice daily orally after meals for 30 days. Recruited patients were advised to carry on their daily activities and exercises that they had been doing before the enrolment and also advised to continue the same till the end of study period.

\section{Statistical analysis:}

Consultant statistician performed the analysis of the data using statistical software SPSS 10.0. Data describing quantitative measures were expressed as median or mean $\pm \mathrm{SD}$ or $\mathrm{SE}$ or the mean with range. Qualitative variables were presented as counts and percentage. Comparison of variables representing categorical data was performed using Chi-square test. All $P$ values are reported based on two-sided significance test and all the statistical tests are interpreted at 5\% level of significance.

\section{Results and Discussion}

Among 20 patients 11 patients were male 9 patients were female. (table2)

Among 20 patients 4 patients were in the age group of 20-30years.11 patients were in the age group of 30-45. 5 patients were in the age group of 45-60.(table 1).Among 20 patients 16 patients had loin pain radiating to groin,11 patients showed frequency of micturition and dysuria, 19 patients had burning micturition, 16 and 14 patients showed nausea and vomiting respectively,6 patients had fever. 3 patients showed oliguria.(table 3). $80 \%$ showed decrease in pain, $80 \%$ showed decrease in frequency of micturition and dysuria , $1 \%$ didn't show response for oliguria, $70 \%$ showed decrease in burning micturition, $10 \%$ didn't show response for haematuria, $75 \%$ and $70 \%$ showed decrease in nausea and vomiting respectively.(bar diagram 2). There was a significant reduction in the size of renal calculi. there were no toxic symptoms, adverse effects, altered haematological investigations for the recommended dosage in clinical trial.

Table 1 age wise distribution

\begin{tabular}{|l|l|l|}
\hline S.NO & $\begin{array}{l}\text { AGE WISE } \\
\text { DISTRIBUTION }\end{array}$ & $\begin{array}{l}\text { NO OF } \\
\text { PATIENTS }\end{array}$ \\
\hline 1 & $20-30$ & 4 \\
\hline 2 & $30-45$ & 11 \\
\hline 3 & $45-60$ & 5 \\
\hline
\end{tabular}

Table 2 Gender wise distribution

\begin{tabular}{|l|l|l|l|}
\hline S.NO & GENDER & NO OF PATIENTS & PERCENTAGE \\
\hline 1 & MALE & 11 & $55 \%$ \\
\hline 2 & FEMALE & 9 & $45 \%$ \\
\hline
\end{tabular}


Int. J. Curr. Res. Med. Sci. (2017). 3(2): 7-14

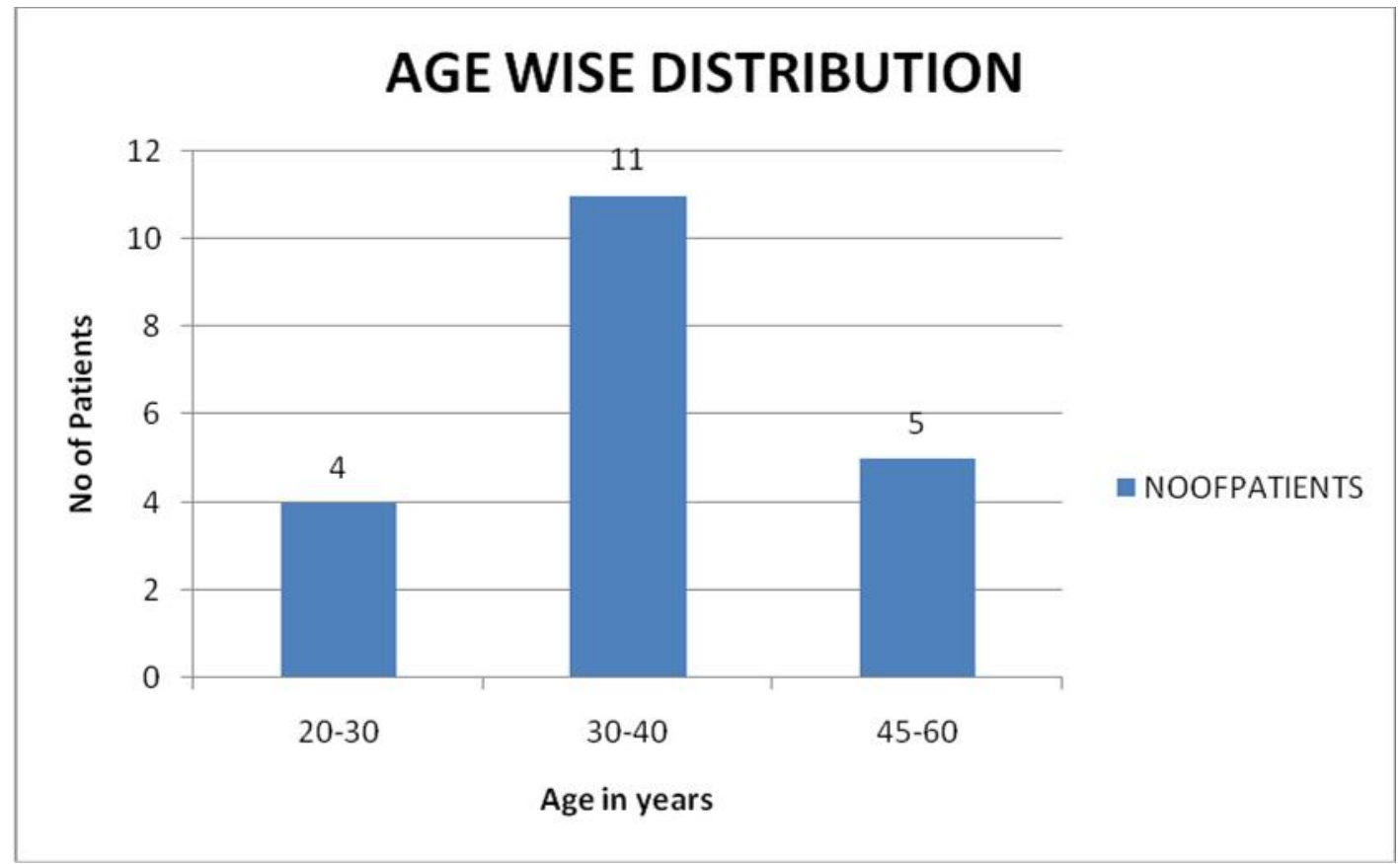

Bar diagram 1

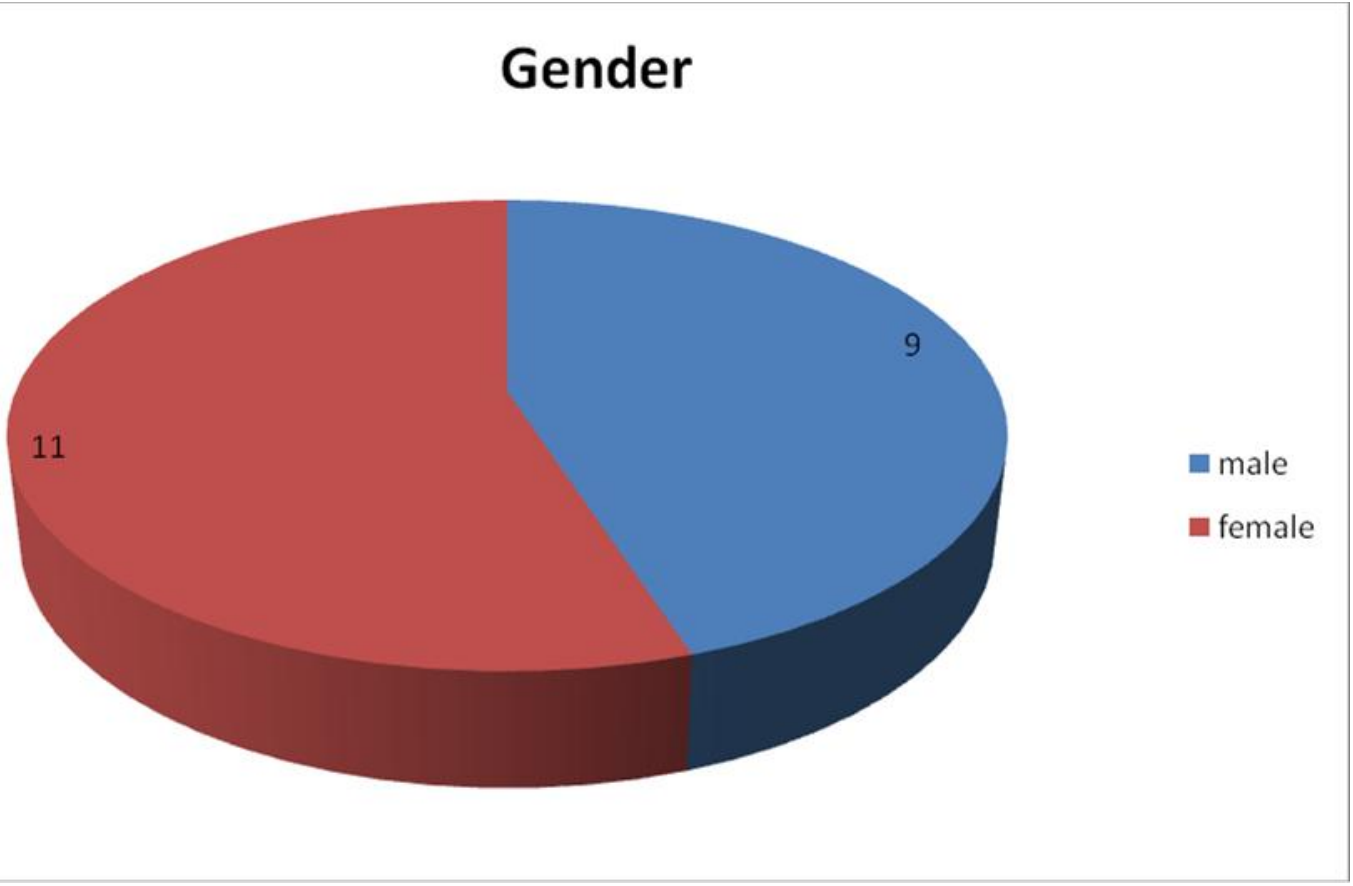

Chart 1 
Int. J. Curr. Res. Med. Sci. (2017). 3(2): 7-14

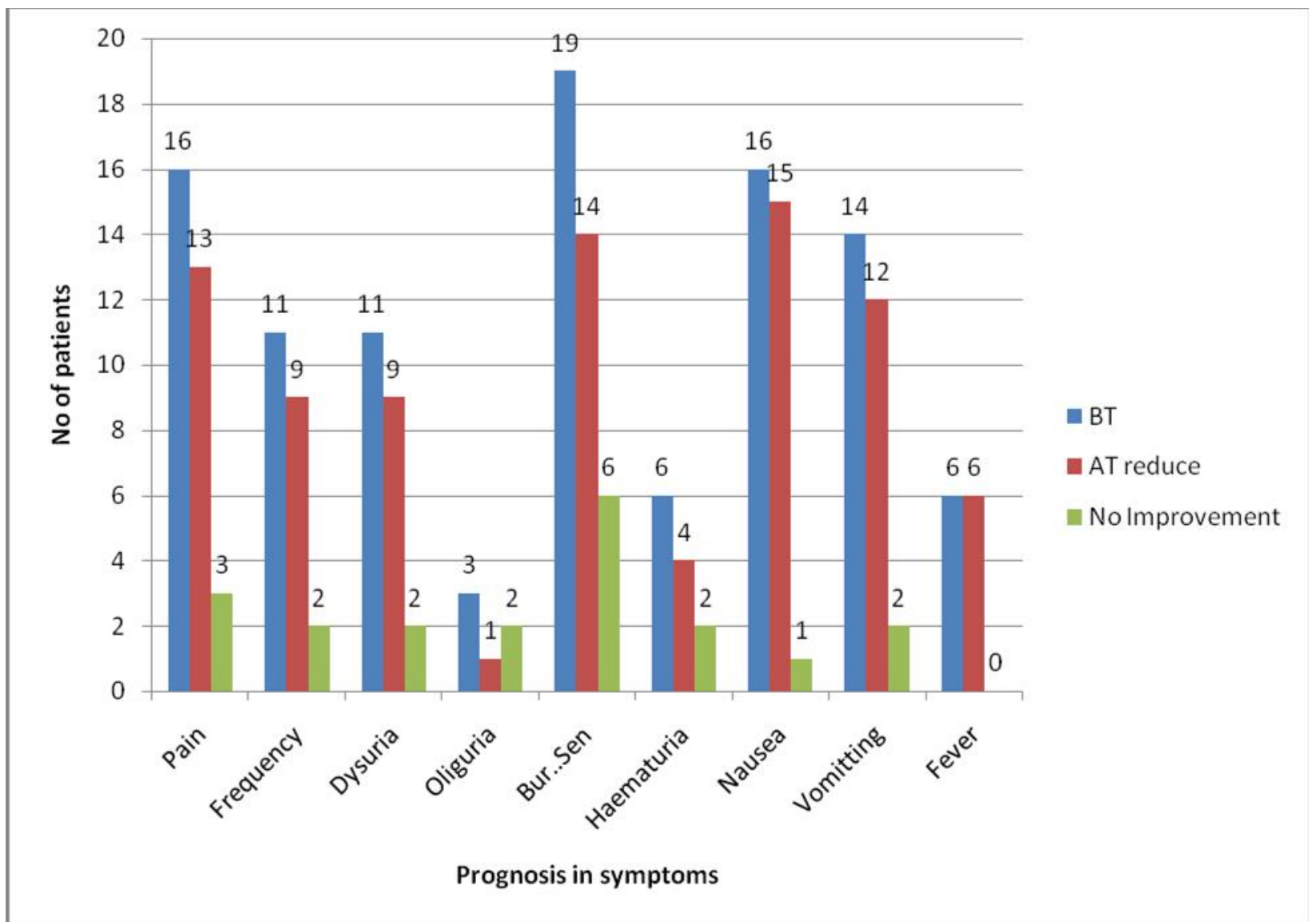

\section{Bar diagram 2}

The drug Sarva Noi Linga Chenduram was selected to find out the lithontriptic activity in the management of Kalladaippu(Renal calculi) .The literary evidence from the text Anuboga Vaidya Navaneetham strongly supported the lithontriptic activity of the drug.

\section{Bio-statistics:}

In prognosis of symptoms Statistical analysispaired ' $t$ ' test "P" value showed 0.240 which was moderately significant shown (Table 4) and for size of renal calculi it showed 0.001 which was highly significant. (Table 5).

Table 3 Prognosis in symptoms of renal calculi

\begin{tabular}{|l|l|l|l|}
\hline S.NO & Symptoms & $\begin{array}{l}\text { No of patients } \\
\text { Before } \\
\text { Treatment }\end{array}$ & $\begin{array}{l}\text { After } \\
\text { Treatment } \\
\text { (prognosis) }\end{array}$ \\
\hline 1 & Pain & 16 & 13 \\
\hline 2 & $\begin{array}{l}\text { Frequency of } \\
\text { micturition }\end{array}$ & 11 & 9 \\
\hline 3 & Dysuria & 11 & 9 \\
\hline 4 & Oliguria & 3 & 1 \\
\hline 5 & Burning micturition & 19 & 14 \\
\hline 6 & Haematuria & 6 & 4 \\
\hline 7 & Nausea & 16 & 15 \\
\hline 8 & Vomiting & 14 & 12 \\
\hline 9 & Fever & 6 & 6 \\
\hline
\end{tabular}


Int. J. Curr. Res. Med. Sci. (2017). 3(2): 7-14

Table :4

\begin{tabular}{|c|c|c|c|c|c|c|}
\hline \multicolumn{6}{|c|}{ Prognosis in symptoms } & \multirow[b]{2}{*}{$P$ value } \\
\hline \multicolumn{2}{|c|}{ variable } & Obs & Mean & Std. & t value & \\
\hline \multirow[t]{2}{*}{ sym } & BT & 20 & 4.75 & 1.118 & \multirow[t]{2}{*}{10.556} & \multirow[t]{2}{*}{0.001} \\
\hline & $\mathrm{AT}$ & 20 & 0.90 & 1.071 & & \\
\hline
\end{tabular}

Table: 5

\begin{tabular}{|c|c|c|c|c|c|c|}
\hline \multicolumn{6}{|c|}{ Reduction in size of renal calculi } & \\
\hline \multicolumn{2}{|c|}{ variable } & Obs & Mean & Std. & t value & \\
\hline \multirow[t]{2}{*}{ size } & BT & 20 & 10.930000 & 5.83610 & \multirow[t]{2}{*}{4.856} & \multirow[t]{2}{*}{$<0.0001$} \\
\hline & AT & 20 & 6.488000 & 4.69628 & & \\
\hline
\end{tabular}

It is mentioned that Lingam(cinnabar) cures the diseases related with fluids and also Venkaram has lithontriptic,diuretic activity. Kidney oxalate stone is the result of supersaturation of urine with certain urinary salts such as calcium oxalate.

An important reason for acute and chronic renal failure, lithiasis, includes both nephrolithiasis and urolithiasis. Medical management of lithiasis, today, includes lithotripsy and surgical procedures. Unfortunately, the underlying risk factors are not corrected by these techniques hence there is a need to continue the medical supervision and therapy to prevent stone recurrence. The recurrence of urolithiasis represents a serious problem as patients who have formed one stone are more likely to form another.

\section{Conclusion}

Ingredients of the Sarva noi linga chenduram have the property of lithontriptic activity. Preclinical evaluation substantiated the textual evidence of this trial medicine. Hence Sarva Noi linga Chenduram can be a better choice of drug in the management of Kalladaippu(Renal calculi).

\section{References}

1.Ahmet Tefekli , Fatin Cezayirli The History of Urinary Stones: In Parallel with Civilization. Scientific World Journal. 2013; 2013: 423964. PMCID: PMC385616.
2.Michelle López and Bernd Hoppe History, Epidemiology and regional diversities ofurolithiasis Pediatr Nephrol. 2010 Jan; 25(1): 49-59. PMCID PMC 2778769.

3.Bartoletti R, Cai T, Mondaini N, Melone F, Travaglini F, Carini M, Rizzo M Epidemiology and risk factors in urolithiasis. Urol Int. 2007;79 Suppl 1:3-7.PMID17726345

4. Sharma AP, Filler G. Epidemiology of pediatric urolithiasis. Indian $\mathrm{J}$ Urol 2010;26:516-22

5.Stamatelou KK, Francis ME, Jones CA, Nyberg LM, Curhan GC: Time trends in reported prevalence of kidney stones in the United States: 1976-1994. Kidney Int 2003; 63:18171823.

6.Lieske JC, Pena de la Vega LS, Slezak JM, Bergstralh EJ, Leibson CL, K-L Ho et al: Renal stone epidemiology in Rochester, Minnesota: An update. Kidney Int 2006; 69:760-764.

7.Colobawalla BN: Incidence of urolithiasis in India: 1971. ICMR Tech Rep Series No 8, 4251.

8..Pendse AK, Singh PP: The Etiology of Urolithiasis in Udaipur (Western Part of India). Urol Res (1986) 14:59-62. 
9.Abdhulla sahib Anupoga vaidhya navaneetham part 4 P.NO 52, 53.

10.Dr R.Thiyagarajan,gunapadam thathu seeva vaguppu, $4^{\text {th }}$ edition 2004 p.no 272 .

11.Dr R.Thiyagarajan,gunapadam thathu seeva vaguppu, $4^{\text {th }}$ edition 2004 p.no 437.

\begin{tabular}{|c|l|}
\hline \multicolumn{2}{|c|}{ Access this Article in Online } \\
\hline 品 & Website: \\
& www.ijcrims.com \\
& Subject: \\
\hline Quick Response Code & \\
\hline
\end{tabular}

How to cite this article:

A. Punitha, S.Visweswaran, A. Rajendra kumar, K.Manickavasakam.(2017). Pilot study of Sarva Noi Linga Chenduram for Lithontriptic activity in the management of renal calculi. (Kalladaippu). Int. J. Curr. Res. Med. Sci. 3(2): 7-14.

DOI: http://dx.doi.org/10.22192/ijcrms.2017.03.02.002 